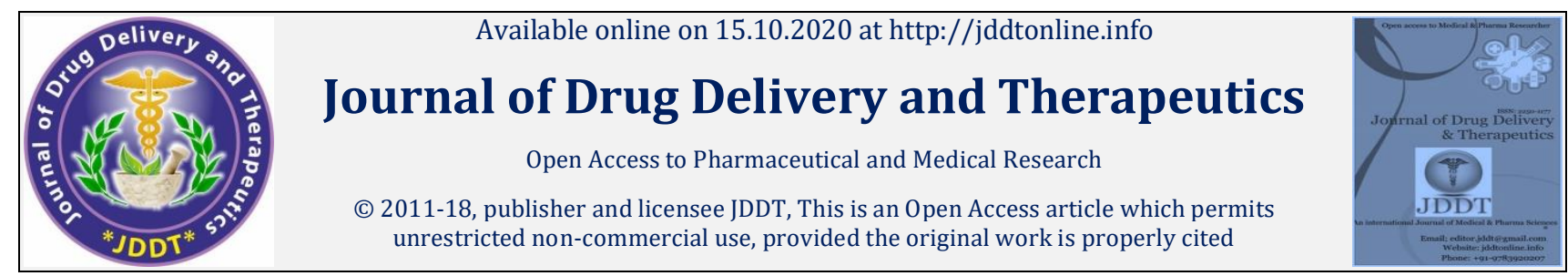

Open 1 Access

Research Article

\title{
Formulation and Evaluation of Solid Lipid Nanoparticles of Olanzapine for the Treatment of Psychosis
}

\author{
Daswadkar Shubhangi C. ${ }^{*}$, Atole Abhijit Vasant ${ }^{2}$ \\ ${ }^{1}$ Associate Professor, Dr. D. Y. Patil College of Pharmacy, Akurdi, Pune, Dr. D. Y. Patil Educational Complex, Sec. No. 29, Akurdi, Pune, India \\ ${ }^{2}$ Dept. of Pharmaceutical Quality Assurance, Dr. D. Y. Patil College of Pharmacy, Akurdi, Pune, Dr. D. Y. Patil Educational Complex, Sec. No. 29, \\ Akurdi, Pune, India
}

\begin{abstract}
Solid lipid nanoparticles (SLN) are typically spherical with an average diameter between $1 \mathrm{~nm}$ to $1000 \mathrm{~nm}$ in range. It is alternative carrier systems to tradition colloidal carriers, such as liposomes emulsions and polymeric micro and nanoparticles. Olanzapine (OZP) is an atypical antipsychotic agent which is used for treatment of Schizophrenia. Its oral bioavailability is around of $40 \%$. OZP is a class II drug so it having low aqueous solubility. To overcome that problem and to increase its bioavailability, the solid lipid nanoparticles of olanzapine are prepared. Formulation batches designed by modifying type of surfactant ( Span 80, Tween 80), concentration of surfactant, Concentration of cosurfactant, type of lipid ( glyceryl monostearate, Stearic acid), Lipid concentration, speed of stirring and time of stirring using customised design of DOE. The SLN were prepared by high speed homogenization technique, and then characterized by particle size analysis, Drug entrapment efficiency and Drug diffusion study. A formulation containing GMS as a lipid stabilised with tween 80 as surfactant show good drug release, smaller particle size, as compared with other formulations with different lipid and surfactant. The present research findings indicate that OZP loaded solid lipid Nano particulate system for delivery of OZP with better efficacy with minimum adverse effects.
\end{abstract}

Keywords: Olanzapine, SLN, GMS, high speed homogenization and DOE.

Article Info: Received 04 Aug 2020; Review Completed 11 Sep 2020; $\quad$ Accepted 18 Sep 2020; $\quad$ Available online 15 Oct 2020

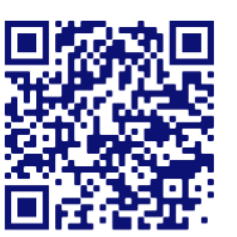

Cite this article as:

Daswadkar SC, Atole AV, Formulation and Evaluation of Solid Lipid Nanoparticles of Olanzapine for the Treatment of Psychosis, Journal of Drug Delivery and Therapeutics. 2020; 10(5-s):25-31 http://dx.doi.org/10.22270/jddt.v10i5-s.4440

*Address for Correspondence:

Educational Complex, Sec. No.29, Akurdi, Pune, India

\section{INTRODUCTION}

A drug's therapeutic efficacy depends on four fundamental pathways of drug transport and modification in the body, absorption, distribution, metabolism and excretion. Failure in therapy includes insufficient drug concentration due to poor absorption, rapid metabolism and elimination, poor drug solubility and high fluctuation of plasma levels due to unpredictable bioavailability ${ }^{1,2}$. A promising strategy to overcome these problems involves the development of suitable drug colloidal carrier system. Among the colloidal carrier systems the solid lipid nanoparticles have many advantages as compare to other colloidal carrier systems ${ }^{3}$.

Solid Lipid Nanoparticles (SLN) recently gained significant attention as potential alternate colloidal drug delivery system for lipid emulsions and liposomes. The advantage of SLN is, it gives more flexibility in controlling to drug release and protects the encapsulated ingredients from the degradation. Also it gives selective bio distribution, in vivo and in vitro drug stability, and better bioavailability ${ }^{3,4}$.

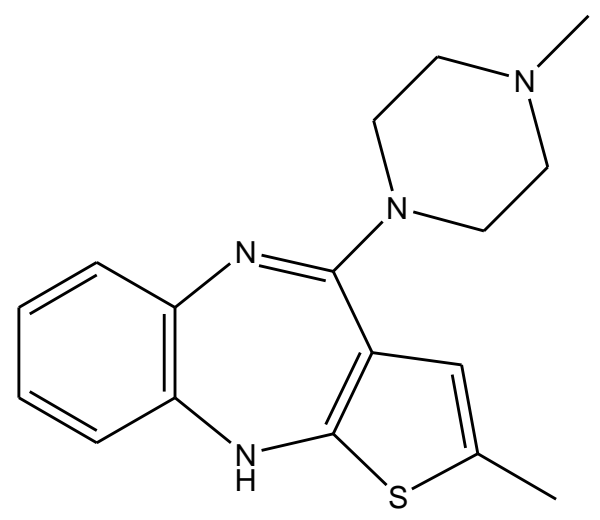

Figure 1 Chemical structure of OZP API 
Olanzapine (approved by FDA in 1996) is a novel antipsychotic agent with broad efficacy, and elicits response in both the positive and negative symptoms of schizophrenia. Clinically, schizophrenia is treated in 3 phases. In the first phase called acute phase, complete hospitalization is a must and lasts for 1-2 months depending on patient's condition. During this period, maximum doses of drugs are given and these are administered forcefully by registered physician or registered nurse, since patient never co-operates with the treatment $2-5$.

As per literature survey various formulations of OZP were reported such as OZP tablets ${ }^{5}$, OZP matrix sustained release tablets ${ }^{6}$, OZP mouth dissolving tablets ${ }^{7}$, OZP matrix pellets ${ }^{8}$, OZPs Micro emulsions ${ }^{9}$ and OZP chitosan nanoparticles ${ }^{10}$. To date, only few attempts have been made to formulate the OZP SLN. So, the aim of present study is to formulate solid lipid nanoparticles with better bioavailability.

\section{MATERIALS AND METHODS}

\section{Materials}

Olanzapine was obtained from Mylan laboratory, Nasik (India) as a gift sample. Gleceryl monostearate, Stearic acid, Polysorbate 80 (Tween 80) and Span 80 were purchased from sigma Aldrich chemicals USA. For formulation double distilled water was used. All the reagents and solvents were used of analytical grade.

\section{Preformulation Studies}

\section{Determination of Melting Point:}

Open capillary tube method was used for determining the melting point of the drug. This procedure was performed in triplicate and mean of three observations is considered as a melting point.

\section{Solubility Study:}

The solubility of the drug was performed by placing of a drug in the conical flask by use of different solvents for 24 hours. This practice was performed thrice and a solvent for analysis of drug was finalized.

\section{FT-IR Spectroscopic Determination:}

The drug was characterized by using of Infrared absorption spectroscopy. The Required quantity of drug was taken and mixed with potassium bromide and packed into the compact disk and spectrum was recorded.

\section{Calibration curve of OZP:}

$10 \mathrm{mg}$ of drug was dissolved in $25 \mathrm{ml}$ of methanol and then volume made upto $100 \mathrm{ml}$ with distilled water to get concentration $100 \mu \mathrm{g} / \mathrm{ml}$. Stock solution was diluted further to get concentration range between $2 \mu \mathrm{g} / \mathrm{ml}$ to $12 \mu \mathrm{g} / \mathrm{ml}$ and absorbance was measured at $226 \mathrm{~nm}$.

\section{Drug Polymer Compatibility Study}

A compatibility study was carried out with potential formulation excipients and drug. API and excipients were mixed in specific quantity and placed in sealed vials for 4 weeks at $40 \mathrm{C} \pm 2 / 75 \% \pm 5 \% \mathrm{RH}$ and $25 \mathrm{C} \pm 2 / 75 \% \pm 5 \% \mathrm{RH}$. After specific time period sample was withdrawn for FTIR study.

\section{Experimental design}

For the formulation of OZP- SLN the High speed homogenization technique was used. With the help of Stat-
Ease Design Expert software and customized factorial design the all formulation batches were formed. For that two types of factors were used i.e. Dependent factors and Independent factors. The particles size in nanometer, drug entrapment in percent and drug diffusion in percent study were the dependent variables and concentration of Lipid $(2.5 \%$ to $7.5 \%)$, Concentration of surfactant ( $1 \%$ to $3 \%$ ), speed of stirrer (10000 rpm to $15000 \mathrm{rpm}$ ) and time for stirring (15 minutes to 45 minutes) were the independent factors. Total 34 batches suggested by design of experiment (Table 1).

\section{Preparation of Solid Lipid Nanoparticles}

Olanzapine loaded Solid- Lipid nanoparticles were prepared by High speed Homogenization technique. First, lipid was heated $5-10^{\circ} \mathrm{C}$ above the melting point of the lipid (GMS/ Stearic acid) and OZP was made to dissolve in it. An aqueous phase was prepared by dissolving surfactant (Tween 80/ Span 80) in water and heated to same temperature of oil phase. Hot oil phase was further added to the hot aqueous phase and subjected to high-speed homogenization (10000 rpm-15000rpm) for specified time (15minutes- 45 minutes) as per DOE (Table no. 1). Thereby produces hot oil in water $(\mathrm{O} / \mathrm{W})$ emulsion. The hot nanoemulsion was then cooled down to room temperature, and then lyophilized the sample.

\section{Evaluation of Solid-lipid Nanoparticles}

\section{Particle size determination}

The particle size distribution was analysed by using of digital electronic optical microscope (Labomed LX-200). One drop of sample was taken from each batch and diluted with $10 \mathrm{ml}$ of dispersion medium (distilled water). Then particle size was determined with the help of digital electronic microscope under the $90 \mathrm{X}$ at room temperature. Then average size of fifteen particles of each formulated batch was taken for analysis.

\section{Drug entrapment efficiency}

The entrapment efficacy (EE) of Solid lipid nanoparticles dispersion was determined by centrifugation method. The SLN dispersion was centrifuged at $2000 \mathrm{rpm}$ for one hour and then collected the supernatant liquid of that dispersion. Then collected liquid was filtered to measure the free drug concentration after making the dilutions with freshly prepared phosphate buffer $\mathrm{pH}$ 6.4. The absorbance was measured at $226 \mathrm{~nm}$. Following formula was used for the calculation of EE:

EE $(\%)=$ Amount of drug in NP (mg)/ Amount of drug added (mg) X 100.

\section{In vitro drug release}

In vitro drug release of OZP SLN was determined using Franz-diffusion cell. The cellophane membrane was mounted between the donar and receptor compartments. The receptor compartment was filled with phosphate buffer $(\mathrm{pH}$ $7.4)$ at $37 \circ$. The solution was stirred at $100 \mathrm{rpm}$. The OZP SLN was placed on cellophane membrane and the compartments were clamped together. One $\mathrm{ml}$ of sample was withdrawn at predetermined time for 24 hours, from receptor compartments and immediately replaced using phosphate buffer after filtering through $0.45 \mu \mathrm{m}$ filter and appropriate dilutions, the sample were analyzed for drug content at $226 \mathrm{~nm}$. 
Table 1: Batches generated by DOE

\begin{tabular}{|c|c|c|c|c|c|c|c|}
\hline Run & $\begin{array}{c}\text { Factor } 1 \\
\text { A: Surfactant } \\
\text { conc. }\end{array}$ & $\begin{array}{c}\text { Factor2 } \\
\text { B: } \\
\text { Co- } \\
\text { surfactant }\end{array}$ & $\begin{array}{c}\text { Factor } 3 \\
\text { C: Lipid } \\
\text { conc. }\end{array}$ & $\begin{array}{l}\text { Factor } 4 \\
\text { D: Time for } \\
\text { Stirring }\end{array}$ & $\begin{array}{l}\text { Factor } 5 \\
\text { E: Speed for } \\
\text { Stirring }\end{array}$ & $\begin{array}{c}\text { Factor } 6 \\
\text { F: Type of } \\
\text { Surfactant }\end{array}$ & $\begin{array}{c}\text { Factor } 7 \\
\text { G: Type of lipid }\end{array}$ \\
\hline 1 & 2.55 & 0.625 & 4.82 & 35.25 & 11700 & Span 80 & Steric acid \\
\hline 2 & 1 & 0.25 & 7.5 & 45 & 15000 & Tween 80 & Steric acid \\
\hline 3 & 1 & 1 & 7.5 & 15 & 10000 & Span 80 & GMS \\
\hline 4 & 2.77 & 0.30 & 6.37 & 15 & 10300 & Tween 80 & Steric acid \\
\hline 5 & 1 & 0.25 & 7.5 & 15 & 10000 & Tween 80 & GMS \\
\hline 6 & 2.5 & 1 & 7.5 & 17.25 & 14000 & Span 80 & Steric acid \\
\hline 7 & 1 & 0.25 & 2.5 & 45 & 10000 & Tween 80 & GMS \\
\hline 8 & 2.99 & 0.25 & 2.5 & 45 & 12947 & Tween 80 & GMS \\
\hline 9 & 3 & 1 & 7.5 & 15 & 10000 & Tween 80 & GMS \\
\hline 10 & 1 & 1 & 2.5 & 45 & 10000 & Span 80 & GMS \\
\hline 11 & 3 & 1 & 2.5 & 15 & 10000 & Span 80 & Steric acid \\
\hline 12 & 1 & 1 & 2.5 & 15 & 10000 & Tween 80 & GMS \\
\hline 13 & 1 & 0.53 & 4.7 & 24.45 & 13050 & Tween 80 & Steric acid \\
\hline 14 & 3 & 0.25 & 2.5 & 15 & 15000 & Tween 80 & Steric acid \\
\hline 15 & 1 & 0.25 & 7.5 & 45 & 10000 & Span 80 & GMS \\
\hline 16 & 1 & 1 & 7.5 & 45 & 10000 & Tween 80 & GMS \\
\hline 17 & 1 & 1 & 7.5 & 45 & 15000 & Span 80 & GMS \\
\hline 18 & 3 & 0.25 & 7.5 & 15 & 15000 & Span 80 & Steric acid \\
\hline 19 & 1 & 1 & 7.5 & 15 & 15000 & Tween 80 & GMS \\
\hline 20 & 1 & 1 & 7.5 & 45 & 10000 & Span 80 & Steric acid \\
\hline 21 & 3 & 0.25 & 2.5 & 15 & 10000 & Span 80 & GMS \\
\hline 22 & 1 & 1 & 2.5 & 45 & 10000 & Tween 80 & Steric acid \\
\hline 23 & 3 & 1 & 2.5 & 15 & 15000 & Span 80 & GMS \\
\hline 24 & 1 & 1 & 7.5 & 15 & 10000 & Tween 80 & Steric acid \\
\hline 25 & 1 & 1 & 2.5 & 45 & 15000 & Tween 80 & GMS \\
\hline 26 & 1 & 1 & 2.5 & 15 & 15000 & Span 80 & Steric acid \\
\hline 27 & 3 & 1 & 7.5 & 45 & 10000 & Span 80 & GMS \\
\hline 28 & 3 & 0.25 & 2.5 & 45 & 15000 & Tween 80 & Steric acid \\
\hline 29 & 1 & 0.25 & 2.5 & 15 & 15000 & Span 80 & GMS \\
\hline 30 & 3 & 0.25 & 7.5 & 45 & 10000 & Tween 80 & Steric acid \\
\hline 31 & 1 & 0.25 & 2.5 & 15 & 10000 & Tween 80 & GMS \\
\hline 32 & 3 & 0.25 & 7.5 & 45 & 15000 & Span 80 & Steric acid \\
\hline 33 & 2.77 & 0.93 & 2.5 & 37.5 & 15000 & Span 80 & GMS \\
\hline 34 & 3 & 1 & 7.5 & 45 & 15000 & Span 80 & Steric acid \\
\hline
\end{tabular}

\section{RESULT AND DISCUSSION}

\section{Preformulation studies}

\section{Melting point determination}

The melting point of OZP API was found to be $188 \pm 2^{\circ} \mathrm{C}$.

\section{Solubility study}

OZP was practically insoluble in water, slightly soluble in Chloroform and freely soluble in Methanol and Ethanol.

\section{FTIR study of OZP}

From the FTIR study characteristics of OZP, amine group obtain at $3229 \mathrm{~cm}^{-1}, \mathrm{C}-\mathrm{H}$ stretching at $2844 \mathrm{~cm}^{-1}$ and $\mathrm{C}=\mathrm{N}$ stretching at $1633 \mathrm{~cm}^{-1}, \mathrm{C}-\mathrm{N}$ stretching at $1258 \mathrm{~cm}^{-1}$.

\section{Calibration curve of OZP}

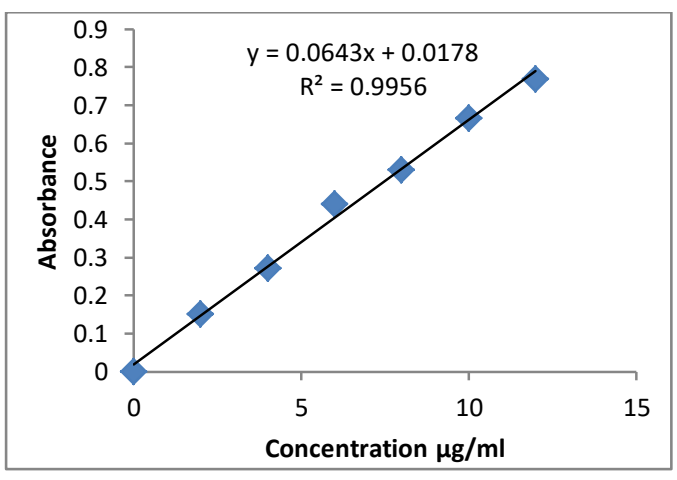

Figure 2: Calibration curve of OZP 


\section{API Compatibility study}

Table 2: API compatibility study

\begin{tabular}{|c|c|c|c|c|c|}
\hline Ingredients & Ratio & Parameters & Initial & $\begin{array}{c}40^{\circ} \mathrm{C} \pm \\
2^{\circ} \mathrm{C} / 75 \% \pm 5 \% \mathrm{RH}\end{array}$ & $\begin{array}{c}25^{\circ} \mathrm{C} \pm \\
2{ }^{\circ} \mathrm{C} / 75 \% \pm 5 \% \mathrm{RH}\end{array}$ \\
\hline \multirow[t]{2}{*}{ API } & \multirow[t]{2}{*}{1} & Appearance & $\begin{array}{c}\text { Solid Yellow } \\
\text { powder }\end{array}$ & As initial & As initial \\
\hline & & Color change & No & No & No \\
\hline \multirow[t]{2}{*}{ API + GMS } & \multirow[t]{2}{*}{$1: 1$} & Appearance & $\begin{array}{l}\text { Solid Yellow } \\
\text { powder }\end{array}$ & As initial & As initial \\
\hline & & Color change & No & No & No \\
\hline \multirow[t]{2}{*}{$\begin{array}{c}\text { API + Stearic } \\
\text { acid }\end{array}$} & \multirow[t]{2}{*}{$1: 1$} & Appearance & $\begin{array}{l}\text { Solid Yellow } \\
\text { powder }\end{array}$ & As initial & As initial \\
\hline & & Color change & No & No & No \\
\hline
\end{tabular}

The compatibility studies between the drug and polymer was evaluated using FTIR spectrophotometry. There was no any significance interaction in IR spectra of drug and excipient.

\section{DOE Results}

Table 3: Evaluation parameters of batches suggested by DOE

\begin{tabular}{|c|c|c|c|}
\hline Run & $\begin{array}{c}\text { Response 1 } \\
\% \text { Entrapment } \pm \text { S.D }\end{array}$ & $\begin{array}{c}\text { Response } 2 \\
\text { Particle size } \pm \text { S.D }\end{array}$ & $\begin{array}{c}\text { Response } 3 \\
\text { Drug diffusion } \pm \text { S.D }\end{array}$ \\
\hline 1 & $66.93 \pm 0.51$ & $715.25 \pm 4.10$ & $69.81 \pm 0.55$ \\
\hline 2 & $65.68 \pm 0.65$ & $825.83 \pm 5.25$ & $61.66 \pm 0.69$ \\
\hline 3 & $63.35 \pm 0.48$ & $894.33 \pm 3.65$ & $63.58 \pm 0.54$ \\
\hline 4 & $67.32 \pm 0.87$ & $792.13 \pm 3.25$ & $61.05 \pm 0.29$ \\
\hline 5 & $66.64 \pm 0.64$ & $912.41 \pm 3.15$ & $64.38 \pm 0.35$ \\
\hline 6 & $62.80 \pm 0.24$ & $792.39 \pm 6.25$ & $64.62 \pm 0.98$ \\
\hline 7 & $72.59 \pm 0.69$ & $768.88 \pm 4.25$ & $69.33 \pm 0.65$ \\
\hline 8 & $79.53 \pm 0.35$ & $631.63 \pm 4.15$ & $79.66 \pm 0.15$ \\
\hline 9 & $72.58 \pm 0.18$ & $775.06 \pm 5.32$ & $72.31 \pm 0.66$ \\
\hline 10 & $69.40 \pm 0.98$ & $756.90 \pm 5.15$ & $71.63 \pm 0.78$ \\
\hline 11 & $66.85 \pm 0.88$ & $712.20 \pm 5.36$ & $70.45 \pm 0.49$ \\
\hline 12 & $63.03 \pm 0.48$ & $850.70 \pm 4.35$ & $64.65 \pm 0.56$ \\
\hline 13 & $66.68 \pm 0.81$ & $855.97 \pm 1.36$ & $59.32 \pm 0.51$ \\
\hline 14 & $67.80 \pm 0.75$ & $725.84 \pm 2.35$ & $68.97 \pm 0.36$ \\
\hline 15 & $70.91 \pm 0.18$ & $812.61 \pm 3.25$ & $69.35 \pm 0.34$ \\
\hline 16 & $70.36 \pm 0.59$ & $818.75 \pm 1.22$ & $66.57 \pm 0.15$ \\
\hline 17 & $70.07 \pm 0.46$ & $797.85 \pm 3.15$ & $68.78 \pm 0.35$ \\
\hline 18 & $67.03 \pm 0.49$ & $767.57 \pm 2.15$ & $67.90 \pm 0.95$ \\
\hline 19 & $65.80 \pm 0.83$ & $894.66 \pm 2.36$ & $60.90 \pm 0.98$ \\
\hline 20 & $62.83 \pm 0.75$ & $816.28 \pm 2.15$ & $62.24 \pm 0.65$ \\
\hline 21 & $72.93 \pm 0.68$ & $710.62 \pm 2.36$ & $75.66 \pm 0.46$ \\
\hline 22 & $63.51 \pm 0.61$ & $778.46 \pm 2.15$ & $63.22 \pm 0.85$ \\
\hline 23 & $73.09 \pm 0.48$ & $687.86 \pm 2.65$ & $75.09 \pm 0.75$ \\
\hline 24 & $58.56 \pm 0.74$ & $924.89 \pm 2.48$ & $55.17 \pm 0.36$ \\
\hline 25 & $70.75 \pm 0.84$ & $753.12 \pm 3.25$ & $68.85 \pm 0.34$ \\
\hline 26 & $58.07 \pm 0.64$ & $828.69 \pm 3.36$ & $58.95 \pm 0.65$ \\
\hline 27 & $77.85 \pm 0.94$ & $685.35 \pm 2.36$ & $78.29 \pm 0.65$ \\
\hline 28 & $71.98 \pm 0.38$ & $628.14 \pm 2.15$ & $74.95 \pm 0.55$ \\
\hline 29 & $65.15 \pm 0.64$ & $837.12 \pm 4.65$ & $65.16 \pm 0.66$ \\
\hline 30 & $72.46 \pm 0.39$ & $703.33 \pm 4.45$ & $71.17 \pm 0.54$ \\
\hline 31 & $57.91 \pm 0.48$ & $856.35 \pm 5.15$ & $59.52 \pm 0.69$ \\
\hline 32 & $79.70 \pm 0.55$ & $684.10 \pm 5.15$ & $76.81 \pm 0.67$ \\
\hline 33 & $70.23 \pm \underline{0.54}$ & $670.80 \pm 5.14$ & $70.65 \pm 0.65$ \\
\hline 34 & $72.62 \pm 0.62$ & $685.58 \pm 5.25$ & $70.60 \pm 0.66$ \\
\hline
\end{tabular}




\section{Particle size analysis}

The effect of lipid (GMS and Stearic acid) and surfactant (Tween 80 and Span 80) concentration on particle size distribution on OZP loaded SLN was showed in Table 3. The particle size was ranged between $625 \mathrm{~nm}$ to $925 \mathrm{~nm}$.

Influence of Surfactant, lipid concentration and speed of stirring on particle size
OZP SLN was prepared using Tween 80 as surfactant showed smaller particle size than span 80 . This may be due to higher molecular weight and higher HLB value of the Tween 80 . When the lipid concentration was above $5 \%$, it requires high speed and more time to break the lipid particles. So, the particle size is increased by using high concentration of lipid content.
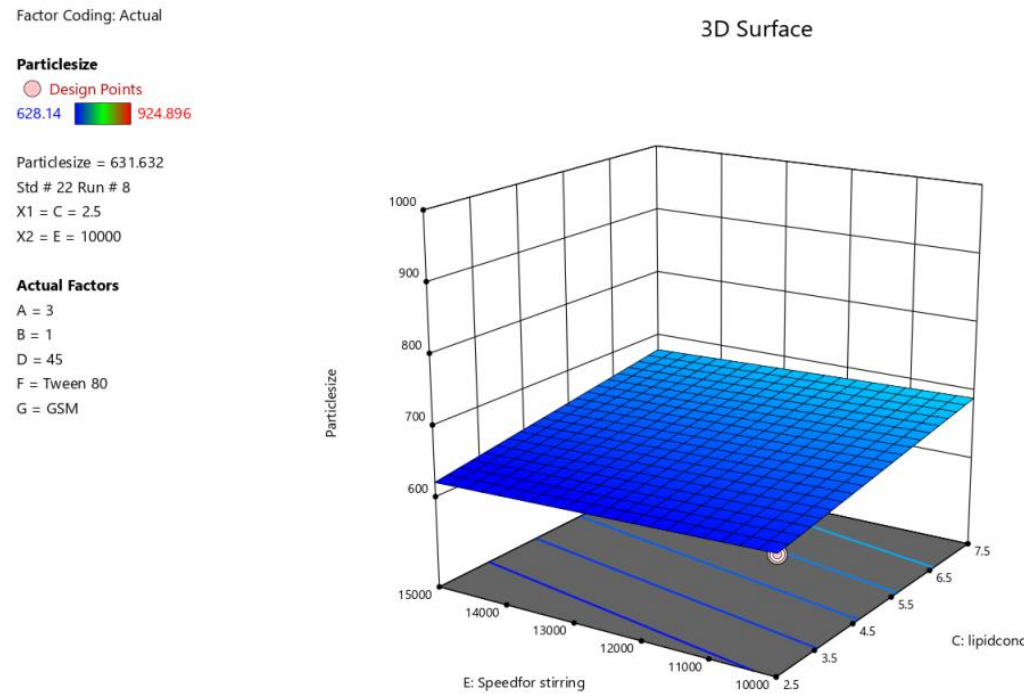

Figure 3: Effect of stirring speed and Lipid concentration on particle size

\section{Drug diffusion}

The drug diffusion of OZP from various SLN formulations is shown in table no.3. The drug diffusion of OZP was found in the range of $55 \%$ to $80 \%$ at the end of 24 hours.
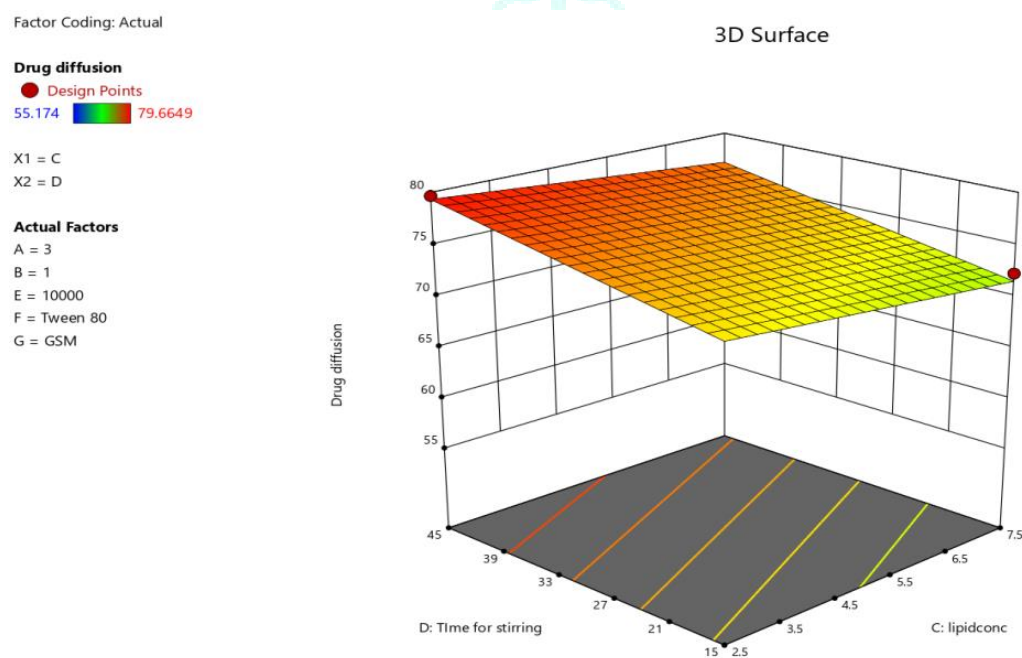

Figure 4: Effect of lipid concentration and stirring time on drug diffusion

\section{Influence of type of lipid, conc. of lipid and time for stirring on drug diffusion}

Formulations containing GMS as a lipid matrix shows higher drug release as compare to stearic acid (GMS $>$ Stearic acid) Stearic acid produced less order crystals than GMS leading to lower drug expulsion from the imperfect lattice. To enhance drug diffusion lipid concentration should be below $5 \%$, and time for stirring above the 20 minutes. When the conc. of lipid increases that time increases conc. of surfactant to increase the lipid matrix and entrapment of drug.

\section{Percent drug entrapment}

In order to attain optimal entrapment efficiency, several factors are varied, including type of lipid, speed of stirring and time for stirring. The EE of all the prepared batches are shown in table No. 3. The EE of SLN dispersions was found in the range of $57 \%$ to $80 \%$.

\section{Effect of surfactant on drug entrapment}

All batches formulated with higher surfactant concentrations shows good entrapment efficiency. Formulations containing Tween 80 as a surfactant shows good entrapment efficacy as compare to Span 80 as a surfactant (fig. 5 ). This could be due to lower HLB value of Span 80 

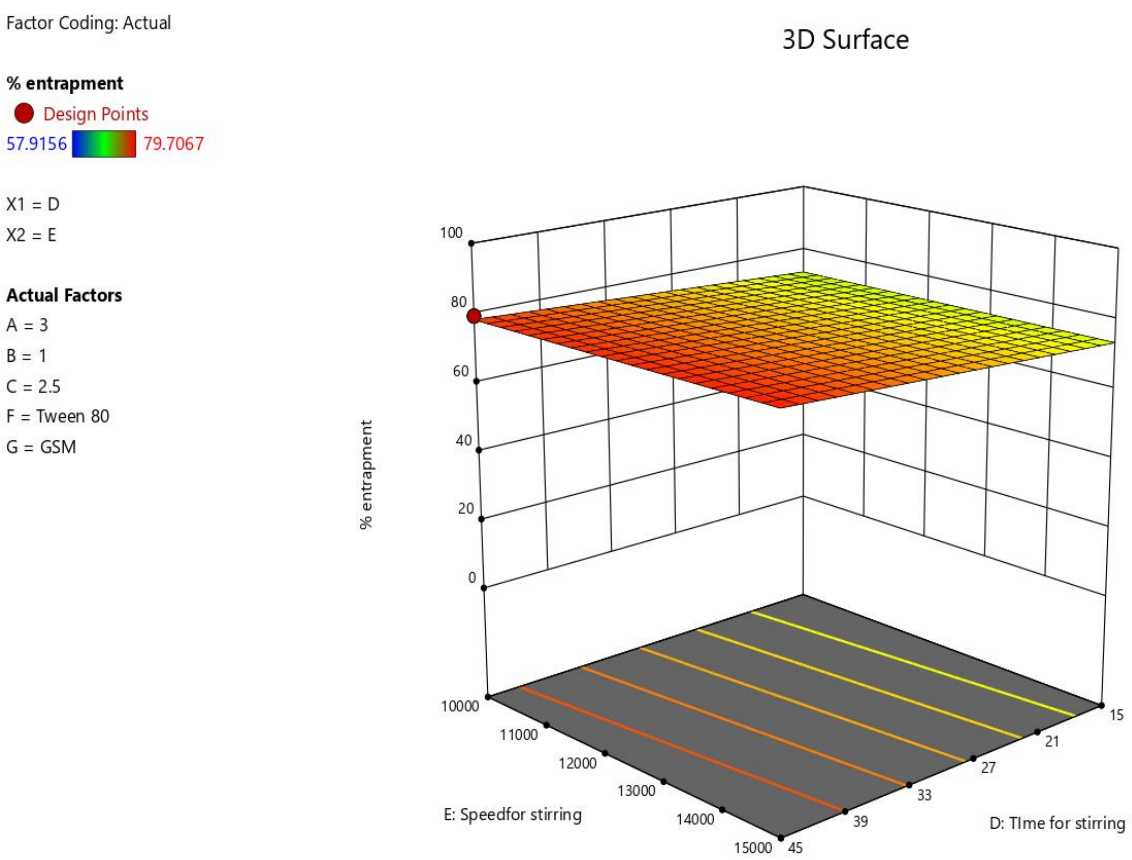

Figure 5: Effect of speed and stirring time on Entrapment efficacy

\section{Effect of speed and time of stirring on $E E$}

When the speed of stirring above the $12000 \mathrm{rpm}$ and time above the 30 minutes it was showed good entrapment efficacy. As the time and speed of stirring was decreases then entrapment efficiency also decreased.

DOE data of 34 formulation batches were obtained based upon that data, F8 batch was found to be significant and finalized as optimized batch and their further evaluation was done.

\section{Optimization of Batch}

The Design-Expert software was used in order to find the optimized conditions for desired formulation. The desirability criteria set in design-expert for optimized formulations were minimum particle size, maximum entrapment efficiency and maximum drug content. The results were obtained significant, when the concentration of Tween 80 2.99\% and Lipid as GMS with concentration 2.5\%, speed of stirring $12900 \mathrm{rpm}$ and stirring time 45 minutes. This was showed desired particles size with better drug diffusion and entrapment efficiency for improved nose to brain targeting drug delivery.

\section{Evaluation of optimized batch}

The evaluation of optimized batch gave particle size approximately $625 \mathrm{~nm}$ to $635 \mathrm{~nm}$ (Figure no. 6) which can easily cross blood brain barrier. Drug diffusion was found in the range of $75 \%$ to $80 \%$ (Figure no. 7) which is greater than oral dosage forms. The percent entrapment of optimized dosage form was found in the range of $76 \%$ to $80 \%$.

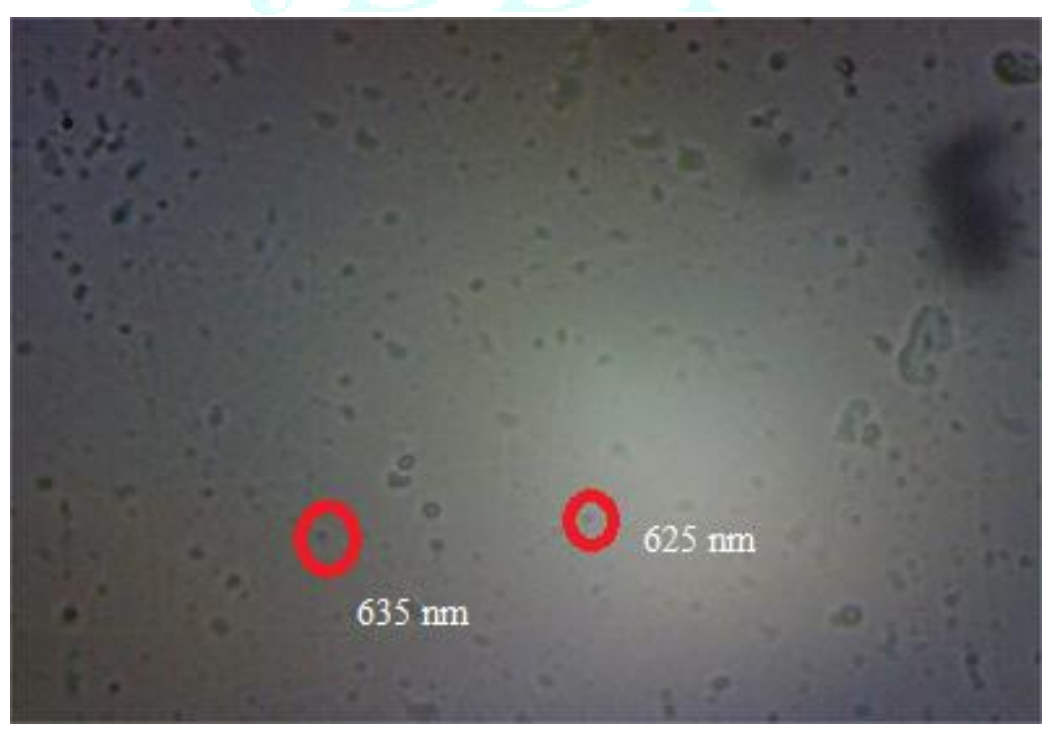

Figure 6: Particle distribution of F8 batch 


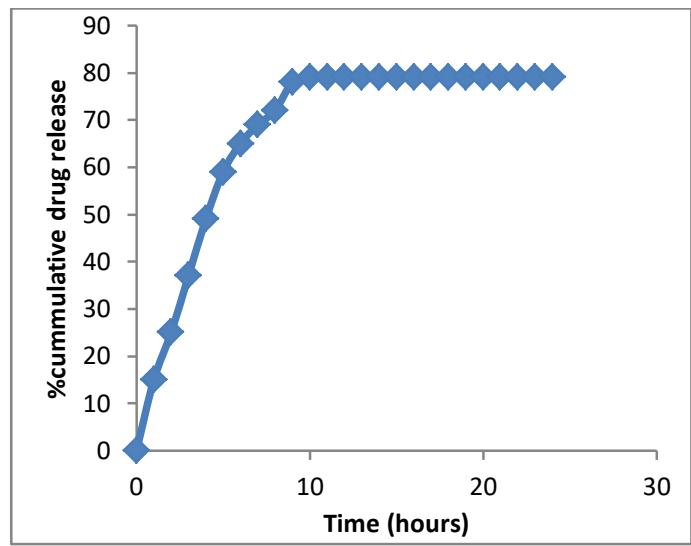

Figure 7: In vitro drug release of $F 8$ batch

\section{CONCLUSION}

Olanzapine was successfully encapsulated into solid lipid nanoparticles by high speed homogenization technique. Various formulations of OZP loaded SLNs were prepared using various process variables. The prepared formulations were evaluated for drug entrapment efficiency; formulation F8 registered highest entrapment of $79 \%$ to $80 \%$. The particle size of F8 formulation found in between $630 \mathrm{~nm}$ to $635 \mathrm{~nm}$. The in-vitro drug release of F8 formulation was found to be $79 \%$ to $80 \%$ over 10 hours in controlled manners, hence the present study was a successful attempt to formulation of OZP by SLN system. Further study is necessary to investigate the exact mechanism related to findings of the study.

\section{REFERENCES}

1. https://www.who.int/mental_health/mhgap/evidence/psychos is/q1/en/

2. Ekambaram P, Sathali H, A. Abdul, Formulation and Evaluation of Solid lipid nanoparticles of Ramipril, Journal of Young pharmacists, 2011; 3(3):216-220.

3. Joseph E, Reddi S, Rinwa V, Balwani G, Saha R, Design and in vivo evaluation of solid lipid nanoparticulate systems of Olanzapine for acute phase schizophreniea treatment: Investigations on antipsychotic potential and adverse effects, European Journal of Pharmaceutical Sciences, 2017; 1(1):1-29.

4. Vivek K, Reddy H, Murthy RSR, "Investigations of the Effect of the Lipid Matrix on Drug Entrapment, In Vitro Release, and Physical Stability of Olanzapine-Loaded Solid Lipid Nanoparticles" AAPS PharmSciTech 2007; 8 (4):1-9.

5. Das AK, Bhanja S, Swetha T, Priyadarshini B, "Formulation and in-vitro evaluation of Olanzapine tablet for Schizophrenia and Bipolar disorder" International Journal of Pharmaceutical sciences and Research, 2014;5(1):148-155.
6. Prasanna Kumar PSS, Vijaya Kumar G, Sravani B, “Design, Formulation and In vitro evaluation of Olanzapine matrix sustained release tablets using natural polymers" World journal of Pharmacy and Pharmaceutical Science, 2017; 6(6):14421459.

7. Maheswarappa MK, Desai PD, "Design and in-vitro evaluation of mouth dissolving tablets of olanzapine" Asian Journal of Pharmaceutics, 2011; 5(1):107-113.

8. Gupta VN, Gowda DV, Balamuralidhara V, Mohammed Khan S, "Formulation and evaluation of olanzapine matrix pellets for controlled release" DARU, 2011; 19(4):249-256.

9. Patel RB, Patel MR, Bhatt KK, Patel BJ, Formulation and Evaluation of Microemulsions- Based drug delivery system for intranasal administration of Olanzapine, International Journal of Biomedical and Pharmaceutical Sciences, 2013; 7 (1):20-27.

10. Pandey VP, Joysa Ruby J, Formulation and evaluation of olanzapine loaded chitosan nanoparticles for nose to brain targeting an in vitro and ex vivo toxicity study, Journal of Applied Pharmaceutical Science, 2016; 6(9):034-040.

11. Sawant KK, Seju U, Kumar A, Development and Evaluation of Olanzapine loaded PLGA nanoparticles for nose to brain delivery: In vitro and In Vivo studies, Acta Biomaterialia, 2011; 7:4169-4176.

12. Kumar M, MIishra A, Mishra AK, Mishra P, Pathak K, Mucoadhesive nanoemulsion-based intranasal drug delivery system of olanzapine for brain targeting, Journal of Drug Targeting, December 2008; 16(10):806-814.

13. Abdelbary GA, Tadros MI, "Brain targeting of olanzapine via intranasal delivery of core - shell difunctional block copolymer mixed nanomicellar carriers: in-vitro characterization, ex-vivo estimation of nasal toxicity and in-vivo biodistribution studies" International Journal of Pharmaceutics, 2013; 1(1):1-51.

14. Farzaneh S, Lish SB, Abdouss M, Asadi E, Azodi-Deilami S, Khonakdar SA, Gharghabi M, Molecularly imprinted polymer nanoparticles for olanzapine recognition: application to solid phase extraction and sustained release" Royal society of chemistry advances, 2014; 1(1):1-46.

15. Vauthier C. Polymer Nanoparticles for In Vivo Applications: Progress on Preparation Methods and Future Challenges, Springer International Publishing Switzerland, 2016; 1:1-16.

16. Iqbala N, Vitorinob C, Taylora KMG. How can lipid nanocarriers improve transdermal delivery of olanzapine, Pharmaceutical Development and Technology, 2016; 1:1-11.

17. Shailaja M, Diwan PV, Ramakrishna Ramesh SG, Reddy KH, Rao YM. Development of Olanzapine Nano-Emulsion for Enhanced Brain Delivery, International Journal of Pharmaceutical Sciences and Nanotechnology, 2012; 5(1):1648-1659.

18. Natarajan J, Baskaran M, Humtose LC, Vadivelan R, Justin A. Enhanced brain targeting efficacy of olanzapine through solid lipid nanoparticles, Journal of artificial cells, nanomedicine, and biotechnology, 2017; 45(2):1-23.

19. Ekambaram P, Abdul Hasan Sathali A, Priyanka K. A review of Solid Lipid Nanoparticles, Journal of Scientific Reviews and Chemical Communications, 2012; 2(1):80-102. 